\title{
RELATIONSHIP BETWEEN URBAN ECOSYSTEM SERVICES AND HUMAN HEALTH RISKS: SYSTEMATIC REVIEW
}

\author{
GABRIELE ZABELSKYTE \& IRINA MATIJOSAITIENE \\ Institute of Environmental Engineering, Kaunas University of Technology, Lithuania
}

\begin{abstract}
Due to urbanization, there is a high demand for research in urban ecosystems linkage to human health risks. By 2050 , around $70 \%$ of the world's population will live in urban areas with the rising challenges of urban space, facilities, and services as well as increasing risks of safety, quality of life, health care, etc. Therefore, there is a great need to analyze the urban ecosystem as an urban planning tool to mitigate human health risks. The main objective of this research is to identify the most and the least investigated urban ecosystems linked to human well-being. The systematic review method is used to analyze the existing literature on ecosystem services' impact on human health risks. Google Scholar, Science Direct, Scopus, and other targeted databases are used for the defined keywords, such as urban ecosystem services and human health, urban ecosystem services and human mental health, etc. Moreover, this paper uses the chronological order and "Word and Word Combination Frequency" method for identified relevant publications. In total, there are 2,498 records analyzed as matching the searched keywords. After the reduction of duplicates, screening, and full article analysis, 107 articles were left for further analysis. The results show that interest in the topic is increasing. Some ecosystem services' linkage to human health risks is more analyzed than others. The majority of analysis is done from a single urban ecosystem perspective (e.g., green infrastructure, water supply), therefore some challenges are defined, such as the lack of research. The majority of previous investigations focus on the urban ecosystem's impact on physical illness. Although the attention towards mental health risks and urban ecosystems is increasing, there are still some gaps because of expensive and long-lasting research. Keywords: urban ecosystem services, human health risks, systematic literature review.
\end{abstract}

\section{INTRODUCTION}

In the last century, the urbanization process increased rapidly: in the 1950s, just less than a third of the population of the world lived in urban areas and projecting that by $2050 \mathrm{~s}$, there will live around $68 \%$ of the world's population [1]. The tendency of the annual growth of people who live in urban areas has social and economic advantages [2], but there are some significant challenges, such as the threat of public health security, quality of life [2]-[4]. Moreover, annual population growth harms the urban environment: infrastructure, urban ecosystems, and other elements of the city. Therefore, there is a need to focus on the relationship between urban ecosystem services (UES) and human health.

The concept of an urban ecosystem (UE) has been analyzed since the end of the 20th century. In general terms, the urban ecosystem describes how natural ecosystems interact with urban areas [5], [6]. Urban ecosystems are the composition of natural and artificial elements, which collaboration has an impact not only on the natural environment but for the social-economic factors, human behavior, institutions [6]. UE can be described as one ecosystem, or to be compiled from unique ecosystems such as wetland, urban parks, urban forests, lakes, and others [6]. Urban ecosystems have their functions in the city, which are described as urban ecosystem services.

The attention of the urban ecosystem services is increasing due to urbanization. Rapid urban population growth leads the city to face significant challenges, such as assurance to a healthy and safe environment. Urban ecosystem services defined as the benefit that society 
receives from the ecosystem function [7]. Moreover, links between the urban ecosystem, their services create a network not only trade-offs in between the services, but also with humans and their well-being [8], [9]. Millennium Ecosystem Assessment [10] describes the relationship between UES and human well-being, which includes human health [11]. Urban ecosystem services are divided into four categories: supporting, provisioning, regulating, and cultural, which are related to human health [10], [12] (Fig. 1).

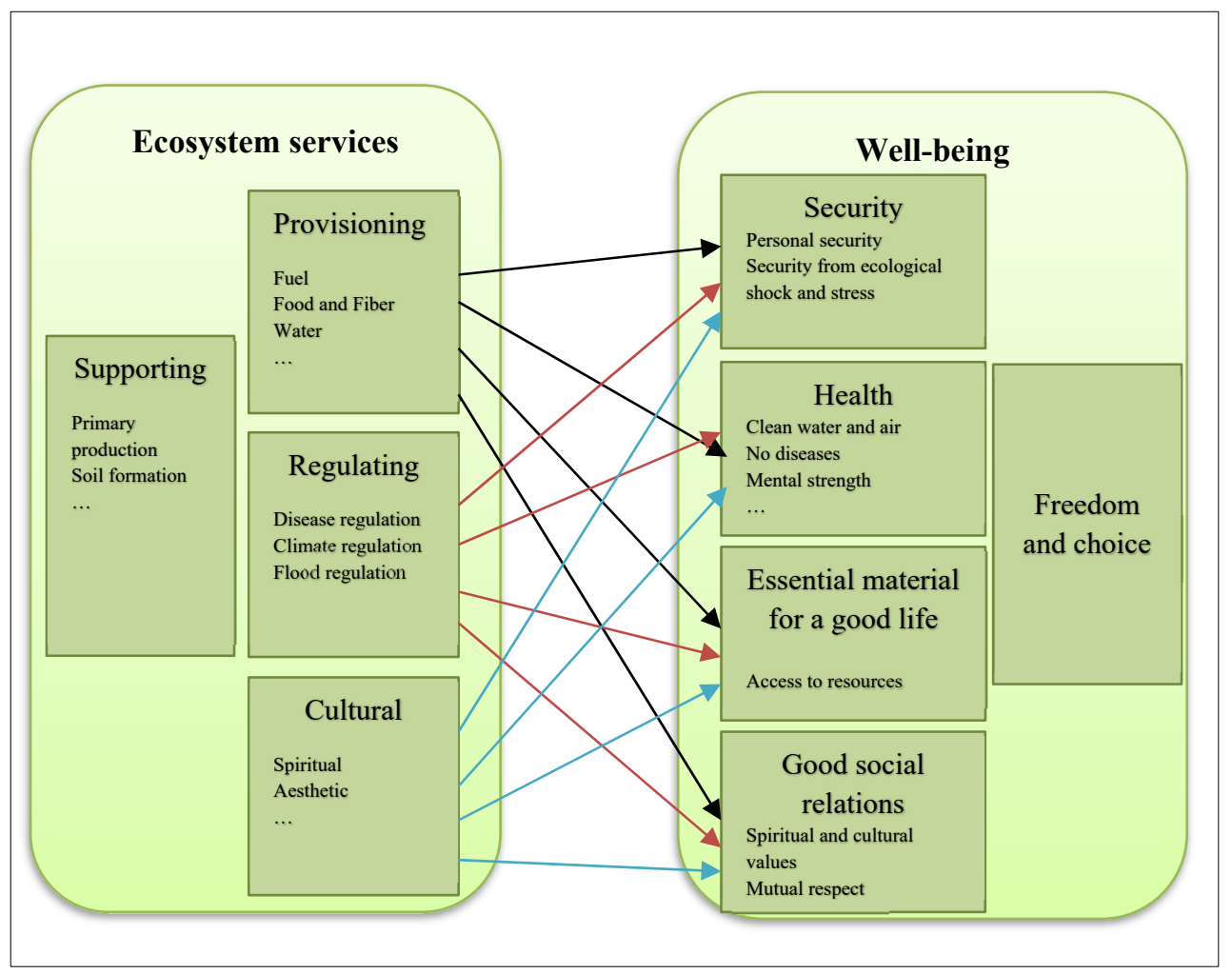

Figure 1: The connection between ecosystem services and well-being [10], [20].

Supporting ecosystem services are described as: "Ecosystem services that are necessary for the production of all other ecosystem services" [13]. Supporting ecosystem services provides water cycling, nutrient cycling, biomass production, atmospheric oxygen production, soil formation and retention, and other services, which are important to the city and its society [14]. Moreover, this group of services is a base for other ecosystem services.

Provisioning services supply to ecosystems, materials (fiber, food, water, and others) that are necessary for the production for all the ecosystem services [9], [15]. Since the city usually is highly populated, there is less space for provisioning services, but one of the usually applicable practices are urban gardens [16]. Urban gardens or school gardens provide some food for locals, for example, vegetables and fruits, but most of it is grown in rural or periurban areas. Nonetheless, the increasing areas of the urban gardens can supply locals, which have more benefits not only for ensuring basic materials but also it improves social and environmental aspects. 
Regulating services is defined as the benefit acquired from the regulation of environmental conditions, such as water purification, climate regulation [17]. Regulating ecosystem services (RES) are important for the environment and human health. RES are both related to physical and psychological health. Air quality directly related to inhaling health problems, such as cardiovascular and respiratory diseases, chronic diseases, and others [18][20]. Nonetheless, green spaces of the city are capable of improving air quality, although there is still an important challenge, such as designing an urban green area since different flora have different characteristics. Regulating ecosystem services plays a crucial role in improving the quality of life.

Cultural ecosystem services are defined as a non-material benefit for the society through aesthetic, spiritual, religious experience, peoples' social benefit, and others [10], [15], [21], [22]. Nonetheless, to increase the positive impact on human health, it is very important to ensure the experience that is provided to humans during the visit of green areas in the city [23]. For example, a well-designed park, with some playgrounds for children, benches for elder society creates pleasure and nice feeling, but if the park has a poor condition, dark/unlighted areas, with no engaging activities, it arises unsafety feeling, which might harm health [24]-[27]. As well, there is another important condition, such as the proximity to the green or blue area. In a poor neighborhood, the areas are less maintained. Consequently, it might have a different impact rather than in a better neighborhood. Consequently, cultural urban ecosystem services are important for human health and well-being.

According to Jackson et al. [28], the ecosystem services that are most relevant to human health can be broadly categorized: air filtration; biodiversity conservation; climate stabilization; habitat maintenance; natural hazard mitigation; food, fuel and fiber production; water filtration; water regulation; and the provision of aesthetic environments and recreational opportunities. Therefore, researches focus on urban ecosystems as a tool to mitigate human health risks.

This paper aims to get deeper insights into the relationship between urban ecosystems and human health. A systematic literature review explains the importance of the topic by showing increasing attention every year, and word frequency technique reveals which word combinations are used the most.

\section{METHODOLOGY}

The research conducts a systematic analysis based on literature review strikethrough based analysis. The search has no limitations according to the date of publication, but only English language papers are included in the analysis. Moreover, extracted records are imported and organized in a reference tool Mendeley. Health and urban term combinations are compiled and applied for the records tracking (Table 1). Defined terms were searched in total in five search engines: PubMed, Science Direct, Web of Science, Google Scholar, and Scopus. The systematic review included papers in the journals, conferences papers, which are not duplicated with the journal papers, excluding books. Moreover, after the screening part, literature reviews are eliminated from the analysis.

\subsection{Google Scholar}

Google Scholar search engine was utilized by using a loop system: all health terms are combined with at least one of urban terms (Table 1). Moreover, the first 60 non-duplicated papers from the combined search terms were screened and included in further literature analysis. In total, there were 364 papers included, which are related to the topic. 
Table 1: Defined keywords for a systematic literature review.

\begin{tabular}{|l|l|}
\hline Urban terms & Health terms \\
\hline Urban ecosystems & Human health \\
Urban ecosystem services & Public health \\
Urban planning & Mental health \\
Green spaces & Illness \\
Green infrastructure & Mental disorders \\
Urban parks & Well being \\
Waste management & \\
Water management & \\
Energy system & \\
\hline
\end{tabular}

\subsection{PubMed}

PubMed search tool is using a similar searching technique to Google Scholar. The importance of this search engine is that this database is more related to medical science. The defined terms are used with the limitation of the title and abstract. In total, there were 1,307 papers extracted, that were found with the combined keywords.

\subsection{Web of Science (WoB), Scopus, and Science Direct (SD)}

Web of Science, Scopus, and Science Direct search engines have similar instructions on managing the tool. There are some minor differences, such as the acronyms for a title, abstract $(\mathrm{WoB}=\mathrm{TI}$, Scopus $=$ Title $)$, the difference in using missing value sign $(\mathrm{WoB}=$ "*”, Scopus "?"). Moreover, terms in SD have to be written with quotation marks. As in PubMed database, defined terms are also are searched only in the title and abstract For example, one of the strings in WoB is conducted: $\mathrm{TI}=((\mathrm{Urban}$ ecosystems OR Urban ecosystem services OR Urban Green space*) AND (Public health OR Human Health OR Mental Health)). Other terms are used in the same way constructed string. From the WoB search engine, 382 records are extracted, 672 from Scopus and 408 from SD.

For the systematic review, Mendeley was used to identify duplicates (Fig. 2). Firstly, in total, there were 64 records excluded as duplicates. Secondly, the screening part was conducted. In this part, the records were removed based on the relevance to the topic: if the title and abstract were not related to defined terms, the article was excluded for further analysis. In this part, 2,037 records did not meet the requirements and were removed. At least, full papers were analyzed to define if the record is relevant to the research. In the last part of the systematic review, 290 records were excluded as not relevant, as well as theoretical approaches and books.

\subsection{Word frequency methodology}

Word frequency technique has been performed by using the Qualitative Data Analysis Software NVivo 12 - QSR International. All the selected 107 articles are imported into the software, and with the function "Word frequency", analysis is conducted. The parameters for the function are: (i) to find 100 the most used words in papers that were selected; (ii) only five or more letter words have to be included in the analysis (to avoid dates, personal pronouns); and (iii) grouping with stemmed words. 


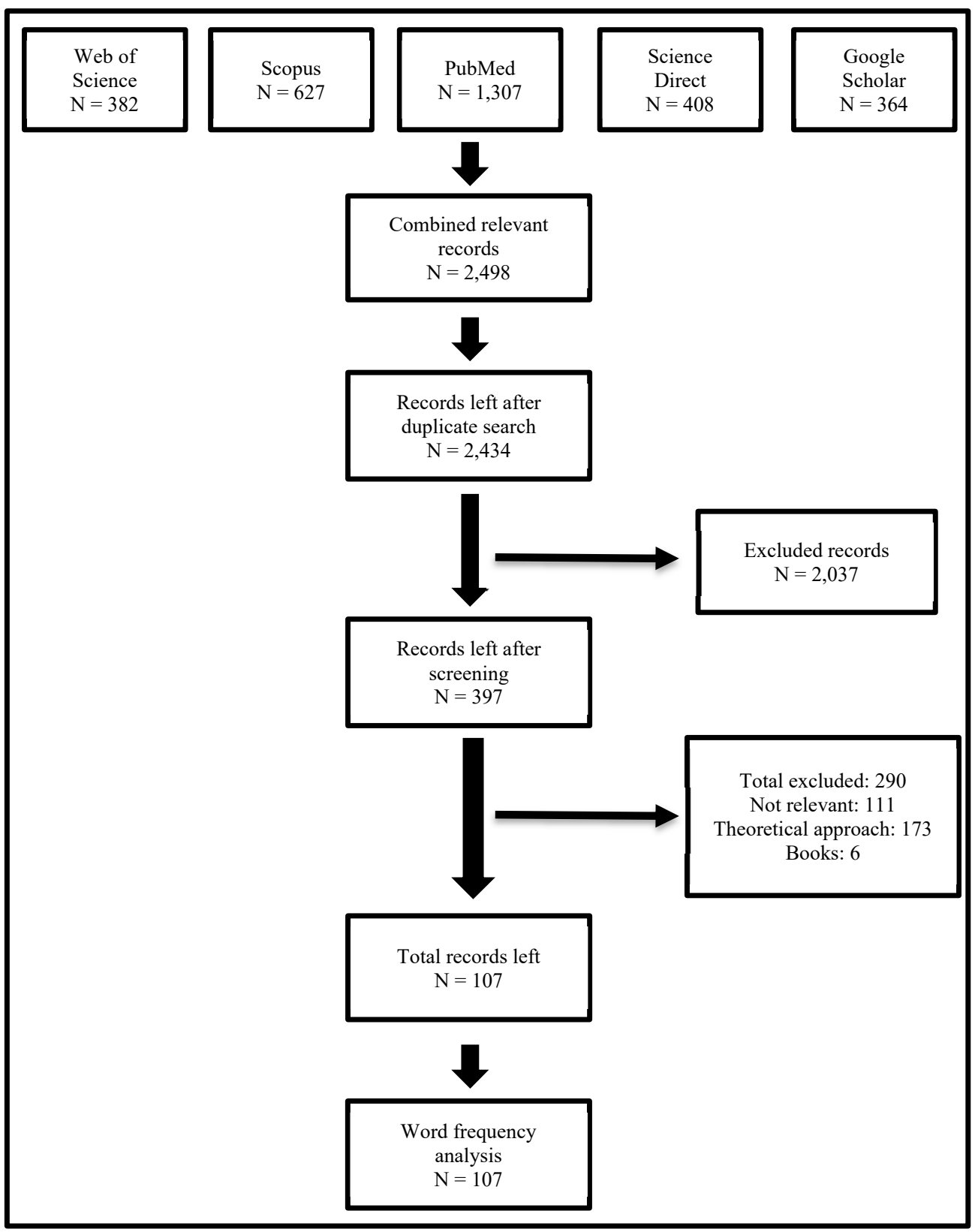

Figure 2: Systematic literature review scheme.

3 RESULTS

After the systematic review analysis, 107 papers have been selected as eligible. Nonetheless, only experimental records are included in the analysis, the number of publications (Fig. 3) 


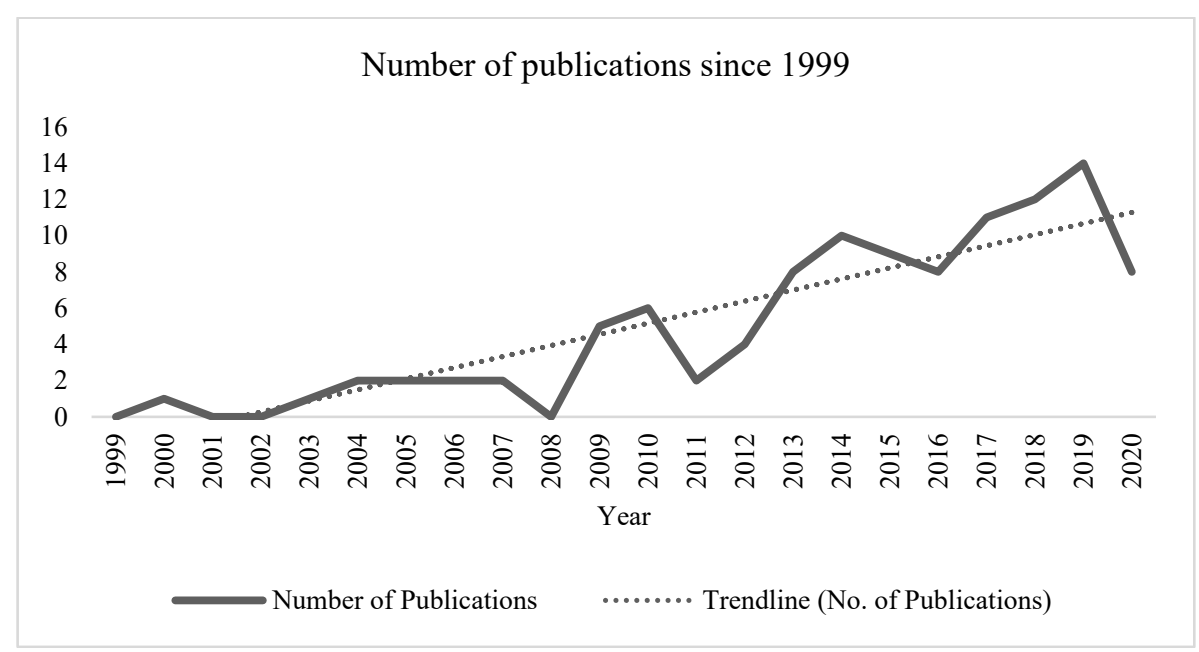

Figure 3: Chronologic publication analysis in the data range 1999-2020.

reveals, that the attention of the topic is increasing. Moreover, the figure shows a decline of publications in 2020 since the analysis has been performed until the 2020 of May.

\subsection{Word frequency analysis}

The results of the word frequency analysis demonstrate that the term greenness (3,199 times) is used the most frequently with the health term (Fig. 4). Other frequently used terms are space' (2,785 times), urban (2,104 times), studying (1,880 times), environments $(1,420$ times), and activity (1,228 times). The cloud clarifies the strongest relationship between human health terms and urban ecosystem services terms.

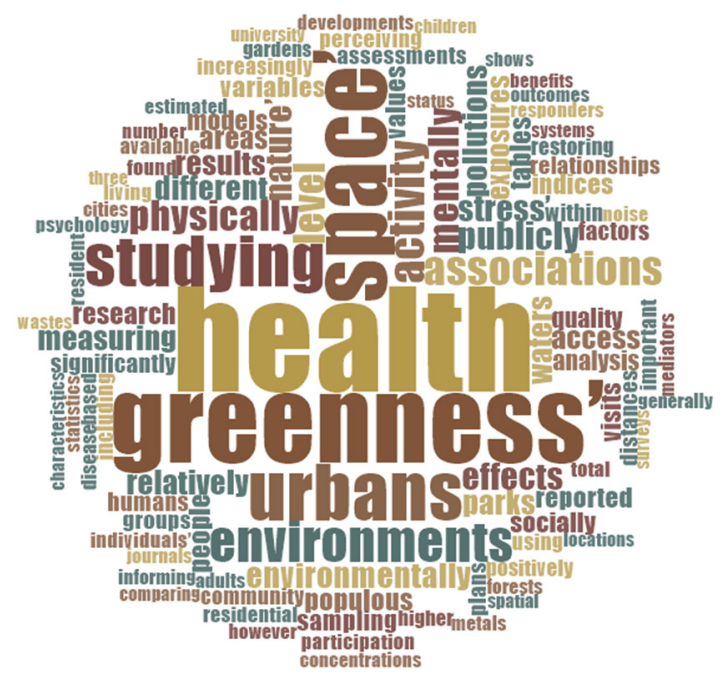

Figure 4: Word frequency cloud. 
3.2 Summary of methods is used to measure the impact on human health.

The summary of methods that are used in the selected records is divided into three main parts: (i) health risks evaluation methods and data gathering; (ii) urban ecosystems evaluation methods and data gathering; and (iii) statistical analysis methods, to evaluate the relationship between two objects (Table 2). The summary is concluded from 35 randomly chosen experiments. Methods analysis and summary show the most often used methodologies in urban ecosystem services evaluation and monitoring.

Table 2: Summary of health, urban ecosystem services, and statistical methods.

\begin{tabular}{|c|c|}
\hline \multicolumn{2}{|r|}{ Health measurements } \\
\hline Parameter & Method \\
\hline Mental and physical health & Questionnaire (usually Likert scale) \\
\hline Mental and physical health & Statistics from a public health institution \\
\hline Physical health & Hormones, blood tests \\
\hline \multicolumn{2}{|c|}{ Urban ecosystem services measurements } \\
\hline Green spaces & Normalized difference vegetation index - NDVI \\
\hline Air quality & $\begin{array}{l}\text { - Measures of air quality/pollution from responsible } \\
\text { institutions } \\
\text { - Modeling tools for pollution distribution } \\
\end{array}$ \\
\hline Water quality & $\begin{array}{l}\text { - Ex-situ and in-situ techniques } \\
\text { - Flame photometric method for dissolved particles } \\
\text { - UV-visible spectrometer for dissolved particles }\end{array}$ \\
\hline Soil quality & $\begin{array}{l}\text { - } \mathrm{pH} \text {, organic matter, electrical conductivity, particle } \\
\text { sizes, texture } \\
\text { - Nir Spectrometer evaluating soil properties }\end{array}$ \\
\hline Noise level & $\begin{array}{l}\text { - Modeling noise level using SoundPLAN, which is an } \\
\text { environmental noise modeling software } \\
\text { - SiRENE (short and long term effects of } \\
\text { transportation noise exposure) determines total } \\
\text { transportation noise from the road }\end{array}$ \\
\hline \multicolumn{2}{|l|}{ Statistical tools } \\
\hline Anova & Durbin test \\
\hline Single and multiple regression & Wu-Hausman F test \\
\hline Logistic regression & Bivariate correlation test \\
\hline Principal components analysis & Chi-square test \\
\hline
\end{tabular}

\section{CONCLUSIONS}

Urban ecosystem services and human health relationship is an important topic since the rapid urbanization raises new challenges. The research shows that every year the topic is getting more attention, but still, there is a high demand for improvements. Moreover, word frequency cloud shows, which aspects are investigated the most and which are investigated less. After reading and analyzing full papers, some differences are explicated. Urban green areas have a higher impact on aging generations' health, rather than younger. As well the significant impact on human health (both physical and mental) has a distance from residents' house and green space - the closer park or green area is to the housing, the better results according to the health. Mainly, it has significant results related to the stress level, anxiety. 
Moreover, the frequency of visiting parks and time spent in the green area has an impact on human well-being [29], [30]. Hence, there are some negative aspects, which cause urban green infrastructure - the level of crimes, insecurity. The Tzoulas et al. study [31] shows that number of crimes is increasing with the increasing number of green infrastructure, which causes fear and insecurity level. Moreover, the unsafety in the city is related to other socioeconomic factors as well, such as age, neighborhood, and cultural background [32]. Although, the physical health evaluation is related to residents' movements, as well as with the environments' quality, such as water, soil, and air pollution, noise level. Mostly, the researchers conduct physico-chemical evaluation methods, assess their risk values, and compare with the World Health Organization (WHO) defined limited values. Noise pollution influences human well-being: it decreases the quality of sleep, causes increasing stress level, which causes other health factors, such as increased blood pressure, concentration problems, and others [33]. Nonetheless, the interest in urban ecosystems as a possible tool to mitigate health is increasing. Still, there is more research needed.

\section{REFERENCES}

[1] United Nations, Department of Economic and Social Affairs, Population Division, World Urbanization Prospects. Demographic Research, United Nations: New York, p. 21, 2019.

[2] Gratz, N.G., Urbanization, arthropod and rodent pests and human health. Proceedings of the 3rd International Conference on Urban Pests, pp. 51-58, 1999.

[3] Leon, D.A., Cities, urbanization and health. International Journal of Epidemiology. 37(1), pp. 4-8, 2008. https://doi.org/10.1093/ije/dym271.

[4] Mcdade, T.W. \& Adair, L.S., Defining the "urban" in urbanization and health. Social Science and Medicine, 53(1), pp. 55-70, 2001. https://doi.org/10.1016/S0277-9536(00)00313-0.

[5] Morse, W.C., McLaughlin, W.J., Wulfhorst, J.D. \& Harvey, C., Social ecological complex adaptive systems: A framework for research on payments for ecosystem services. Urban Ecosystems, 16(1), pp. 53-77, 2013. https://doi.org/10.1007/s11252-011-0178-3.

[6] Alberti, M., Modeling the urban ecosystem: A conceptual framework. Environment and Planning B: Planning and Design, 26, pp. 605-630, 1999.

[7] Gómez-Baggethun, E. \& Barton, D.N., Classifying and valuing ecosystem services for urban planning. Ecological Economics, 86, pp. 235-245, 2013. http://dx.doi.org/10.1016/j.ecolecon.2012.08.019.

[8] Gonza, A., Berbe, M. \& Pascual, U., Towards an ecosystem services approach that addresses social power relations. Current Opinion in Environmental Sustainability, pp. 134-143, 2016. https://doi.org/10.1016/j.cosust.2016.02.003.

[9] Luederitz, C. et al., A review of urban ecosystem services: Six key challenges for future research. Ecosystem Services, 14, pp. 98-112, 2015. http://dx.doi.org/10.1016/j.ecoser.2015.05.001.

[10] Millennium Ecosystem Assessment, Ecosystems and Human Well-being: A Framework for Assessment, Island Press: Washington, DC, pp. 71-84, 2003.

[11] Bayles, B.R. et al., Ecosystem services connect environmental change to human health outcomes. Ecohealth, 13, pp 443-449, 2016. https://doi.org/10.1007/s10393-016-1137-5.

[12] Perring, M.P., Manning, P., Lugo, A.E. \& Ramalho, C.E., Novel Urban Ecosystems and Ecosystem Services, Wiley: Hoboken, NJ, pp. 310-325, 2012. 
[13] Millennium Ecosystem Assessment, Ecosystems and Human Well-being: Synthesis, Island Press: Washington, DC, p. 40, 2005.

[14] Brady, M.V et al., Valuing supporting soil ecosystem services in agriculture: A natural capital approach. Agronomy Journal, pp. 1-56, 2015.

https://doi.org/10.2134/agronj14.0597.

[15] Anderson, P.M.L., Okereke, C., Rudd, A. \& Parnell, S., Regional Assessment of Africa. Urbanization, Biodiversity and Ecosystem Services: Challenges and Opportunities: A Global Assessment, Springer: Dordrecht, pp. 453-459, 2013. https://doi.org/10.1007/978-94-007-7088-1.

[16] Russo, A., Escobedo, F.J., Cirella, G.T. \& Zerbe, S., Edible green infrastructure: An approach and review of provisioning ecosystem services and disservices in urban environments. Agriculture, Ecosystems and Environment, 242(4), pp. 53-66, 2017. http://dx.doi.org/10.1016/j.agee.2017.03.026.

[17] Cortinovis, C. \& Geneletti, D., A framework to explore the effects of urban planning decisions on regulating ecosystem services in cities. Ecosystem Services, 38, 2019. https://doi.org/10.1016/j.ecoser.2019.100946.

[18] Eisenman, T.S. et al., Urban trees, air quality, and asthma: An interdisciplinary review. Landscape Urban Planning, 187, pp. 47-59, 2019. https://doi.org/10.1016/j.landurbplan.2019.02.010.

[19] Ghorani-Azam, A., Riahi-Zanjani, B. \& Balali-Mood, M., Effects of air pollution on human health and practical measures for prevention in Iran. Journal of Research in Medical Sciences: The Official Journal of Isfahan University of Medical Sciences, 21, p. 65, 2016. https://doi.org/10.4103/1735-1995.189646.

[20] Baral, H. \& Holmgren, P., A Framework for Measuring Sustainability Outcomes for Landscape Investments, Center for International Forestry Research (CIFOR): Bogor, Indonesia, 2015. https://doi.org/10.17528/cifor/005761.

[21] Jennings, V.\& Bamkole, O., The relationship between social cohesion and urban green space: An avenue for health promotion. International Journal of Environmental Research and Public Health, 16(3), 2019. https://doi.org/10.3390/ijerph16030452.

[22] Riechers, M., Strack, M., Barkmann, J. \& Tscharntke, T., Cultural ecosystem services provided by urban green change along an urban-periurban gradient. Sustainability, 11(3), pp. 1-10, 2019. https://doi.org/10.3390/su11030645.

[23] Ngulani, T. \& Shackleton, C.M., Use of public urban green spaces for spiritual services in Bulawayo, Zimbabwe. Urban Forestry and Urban Greening, 38, pp. 97-104, 2019. https://doi.org/10.1016/j.ufug.2018.11.009.

[24] Dobbinson, S.J. et al., Study protocol for a natural experiment in a lower socioeconomic area to examine the health-related effects of refurbishment to parks including built-shade (ShadePlus). BMJ Open, 7(2), 2017.

http://dx.doi.org/10.1136/bmjopen-2016-013493.

[25] Foster, S., Knuiman, M., Wood, L. \& Giles-Corti, B., Suburban neighbourhood design: Associations with fear of crime versus perceived crime risk. Journal of Environmental Psychology, 36, pp. 112-117, 2013. http://dx.doi.org/10.1016/j.jenvp.2013.07.015.

[26] Sohn, D.-W. Residential crimes and neighbourhood built environment: Assessing the effectiveness of crime prevention through environmental design (CPTED). Cities, $\mathbf{5 2}$, pp. 86-93, 2016. https://doi.org/10.1016/j.cities.2015.11.023.

[27] Matijosaitiene, I., Combination of CPTED and space syntax for the analysis of crime. Safer Communities, 15(1), pp. 49-62, 2016.

https://doi.org/10.1108/SC-05-2015-0013. 
[28] Jackson, L.E., Daniel, J., Mccorkle, B., Sears, A. \& Bush, K.F., Linking ecosystem services and human health: The eco-health relationship browser. International Journal of Public Health, 58(5), pp. 747-755, 2013. https://doi.org/10.1007/s00038-013-0482-1.

[29] Grilli, G., Mohan, G. \& Curtis, J., Public park attributes, park visits, and associated health status. Landscape and Urban Planning, 199, 2020. https://doi.org/10.1016/j.landurbplan.2020.103814.

[30] Kim, G. \& Miller, P.A., The impact of green infrastructure on human health and wellbeing: The example of the Huckleberry Trail and the Heritage Community Park and Natural Area in Blacksburg, Virginia. Sustainable Cities and Society, 48, 2019. https://doi.org/10.1016/j.scs.2019.101562.

[31] Tzoulas, K. et al., Promoting ecosystem and human health in urban areas using green infrastructure: A literature review. Landscape and Urban Planning, 81(3), pp. 167178, 2007. https://doi.org/10.1016/j.landurbplan.2007.02.001.

[32] Wilkerson, M.L. et al., The role of socio-economic factors in planning and managing urban ecosystem services. Ecosystem Services, 31, pp. 102-110, 2018. https://doi.org/10.1016/j.ecoser.2018.02.017.

[33] Gidlof-Gunnarsson, A. \& Ohrstrom, E., Noise and well-being in urban residential environments: The potential role of perceived availability to nearby green areas. Landscape and Urban Planning, 83, pp. 115-126, 2007. https://doi.org/10.1016/j.landurbplan.2007.03.003. 